\title{
Adaptation of a Community-based Type-2 Diabetes Mellitus Remission Intervention During COVID-19: Empowering Persons Living With Diabetes to Take Control
}

Kim Quimby ( $\sim$ kim.quimby@cavehill.uwi.edu )

The University of the West Indies https://orcid.org/0000-0001-8056-0187

Madhuvanti Murphy

The University of the West Indies

Heather Harewood

The University of the West Indies

Christina Howitt

The University of the West Indies

lan Hambleton

The University of the West Indies

Selvi Jeyaseelan

The University of the West Indies

Natalie Greaves

The University of the West Indies

Natasha Sobers

The University of the West Indies

\section{Short report}

Keywords: community intervention, online intervention, adaptation, modification, fidelity, self-monitor, lowcalorie diet, T2DM remission, weight loss, COVID-19

Posted Date: May 7th, 2021

DOl: https://doi.org/10.21203/rs.3.rs-487308/v1

License: (c) (1) This work is licensed under a Creative Commons Attribution 4.0 International License. Read Full License 


\section{Abstract}

Background: The Barbados Diabetes Remission Study-2 reported that a community-based low-calorie diet (LCD) for weight loss and diabetes remission was both an acceptable implementation strategy and a clinically effective intervention. This study aimed to examine the adaptability of the face-to-face BDRS-2 protocol into an online modality.

Methods: The Iterative Decision-making for Evaluation of Adaptations framework questions the necessity of the adaptation and the preservation of core elements of the intervention during the adaptation process - these elements were identified as the 12-week intervention duration, weekly monitoring of participants for change in weight and fasting blood glucose and daily $840 \mathrm{kcal}$ allowance. The adaptation outcomes were documented using the framework for reporting adaptations and modifications to evidence-based interventions. Implementation effectiveness was determined by fidelity to core intervention elements. Intervention effectiveness was determined from the analysis of clinical data.

Results: We decided that an adaptation was needed as the COVID-19 measures to control transmission prohibited in-person interactions, and that key elements of the intervention could be preserved during the adaptation process.

Adaptations were made to the following: (1) The context in which the data was collected: participants self-measured at home instead of being measured by community health advocates (CHA) at a community site. (2) The context in which the data was entered: participants first posted their measurements to a mobile application site which was accessible by the CHAs. As with the original protocol, CHAs then entered the measurements into an online database. (3) The formulation of the LCD: participants substituted the liquid formulation for a solid meal plan of equivalent caloric content.

There was increased fidelity to the attendance schedule with the online format ( 1 incomplete entry out of 45 entries), as compared to the face-to-face modality (1 absence out of 20 visits). Regarding the solid meal plan, 1 participant logged difficultly averaging non-exact potion sizes.

Weight change ranged from $-14.3 \mathrm{kgs}$ to $0.4 \mathrm{kgs}$ over the 12 -week period and all group members achieved induction of diabetes remission.

Conclusion: Larger studies are needed to confirm that this adapted online protocol is both acceptable and clinically effective while maintaining fidelity to key elements of the original protocol.

Trial Registration: NCT03536377 registered $24^{\text {th }}$ May 2018 at

https://clinicaltrials.gov/ct2/show/NCT03536377

\section{Contribution To The Literature}

- The parent study showed that a community-based low-calorie dietary intervention is acceptable and clinical effective at inducing weight loss and diabetes remission. 
- Restrictions, because of the COVID-19 pandemic, prohibited this face-to-face format. In response, we implemented a modified protocol which was fully online, and included participants self-monitoring at home and posting the results to an online platform, which also doubled as a social support network.

- Fidelity to the core elements of the intervention was maintained during the adaptation.

- The adapted protocol was acceptable and clinically effective at inducing weight loss and diabetes remission.

\section{Background}

Care regimens that place the primary responsibility of disease monitoring on the healthcare system can be problematic as factors such as access, cost and prolonged waiting room times act as deterrents to utilization $(1,2)$. This is particularly true in low-resource settings where Universal Health Coverage has not been fully realised. The impact of these hinderances to access were exacerbated during the COVID-19 pandemic as an estimated $49 \%$ of diabetes services were interrupted as clinical staff from noncommunicable diseases (NCD) clinics were reassigned to COVID-19 support roles (3). Whilst some countries have instituted additional diabetes community clinics, this may not be possible in underresourced areas, thereby compounding disparities in access (4). As persons with diabetes are at risk for poorer clinical outcome if infected with COVID-19, such patients may choose to avoid activities outside of the home including doctors' visits, thereby challenging the concept of acceptability of the ambulatory care model in these times $(5,6)$. Community-based interventions that leverage the use of virtual modalities may help to close the gap in access to care in settings where the internet is accessible (7).

In this article, we discuss the modifications made to the parent article entitled "The impact of a community-based low-calorie intervention on the induction of type-2 diabetes and pre-diabetes remission: A feasibility study utilising a type-2 hybrid design" (8). The implementation strategy was based on a community health advocate ( $\mathrm{CHA}$ ) training model, utilising three faith-based organisations (FBOs) as community intervention sites. During the implementation phase, volunteer congregants participated in a 10-week course where they were taught to measure weight, blood glucose and blood pressure (BP); this was followed by a mandatory, summative practical examination which determined their eligibility to perform the $\mathrm{CHA}$ role during the intervention phase. The intervention was a 12-week low-calorie diet (LCD) of mainly the commercial liquid formulation Glucerna ${ }^{\circledR}$. The daily caloric allowance was $840 \mathrm{kcal}$. Participants were persons who were diagnosed with T2DM for $\leq 6 y$ ears or pre-diabetes and were overweight (BMI $\geq 27$ ). During the intervention phase, participants had their weight, fasting blood glucose (FBG) and BP measured weekly by the $\mathrm{CHA}$ at the $\mathrm{FBO}$. Communication between participants and $\mathrm{CHAs}$ continued during the week via group WhatsApp chats, which were divided by FBO site. $\mathrm{HbA} 1 \mathrm{C}$ was performed at week 1 and 12 only. We reported that this implementation strategy was acceptable to CHAs and participants, and that the intervention under these circumstances was clinically effective at inducing weight loss and T2DM and pre-diabetes remission in a subset of the first cohort of 31 participants.

During the recruitment of the second cohort, the enrolment process was suspended due to the threat of COVID-19, however the five participants that were already enrolled began the LCD. There were all 
previously diagnosed with T2DM and were all at a single FBO site. Following the threat of COVID-19 to our region, these five participants were instructed on how to self-monitor for weight, FBG and BP; and issued with scales, glucometers and BP kits as necessary, as we anticipated a national lockdown. During week 3 of the 12-week intervention, the government instituted a 'work from home' curfew for all nonessential services. Under these directives, all face-to-face contact on the study was aborted.

Here, we describe how the study was adapted to overcome the barriers associated with the COVID-19 directives. The decision to adapt was guided by the Iterative Decision-making for Evaluation of Adaptations (IDEA) tool which included noting the need for the adaptation, determining if fidelity to key intervention components will be preserved and evaluating the intervention outcomes in comparison to the original protocol (9). The adaptation outcomes were also documented, using the framework for reporting adaptations and modifications to evidence-based interventions (FRAME); this records the reasons for and the nature of the adaptation process (10).

\section{Methods}

Within the implementation science literature, the terms 'adaptation' and 'modification' have been used interchangeably. Some articles however have defined modifications as any change to the intervention whereas adaptations are restricted to those changes which were planned or proactive in nature (10). Here, we used the terms as outlined by Moore et al - 'proactive adaptation' for those changes that were planned prior to the intervention phase and 'reactive adaptation' for the changes that were made in response to unforeseen events (11).

\section{The Decision to adapt}

The decision to adapt was guided by three questions that comprise the IDEA tool: (1) Is an adaptation needed? (2) Are the core elements of the intervention known? (3) Can the barrier be addressed while preserving the core elements?

\section{Adaptation outcomes}

The outcomes of the adaptations made during this study were characterised using the FRAME, which considers (1) when the modification occurred (2) if the adaptations were planned (3) who participated in the decision to modify and (4) what was modified (10).

\section{Implementation effectiveness}

Implementation effectiveness was determined by the fidelity to the three core elements of the intervention during the period of the adapted protocol. Fidelity to the 12-week intervention duration was determined from the attendance register, fidelity to the weekly monitoring of participants for change in weight and fasting blood glucose was assessed from the weekly WhatsApp data entry of clinical measurements by participants and fidelity to the daily $840 \mathrm{kcal}$ allowance was gauged from the online conversations and weekly dietary recall. 


\section{Intervention outcomes}

Summary data including change in weight, fasting blood glucose, $\mathrm{HbA} 1 \mathrm{C}$ and the induction of T2DM remission were analysed from the participant data entries.

\section{Results}

\section{The Decision to adapt}

It was determined that adaptation was necessary as the existing COVID-19-related public health policy prohibited the intervention to continue in the original face-to-face format. The core elements of the intervention were identified as (1) the 12-week duration of the study (2) the weekly monitoring and (3) the $840 \mathrm{kcal}$ daily calorie consumption. We decided that the adaptation, which would be contextual in nature, can be implemented without compromising fidelity to the core intervention elements. Based on this paradigm the decision was made to proceed with the adaptation and evaluate the intervention outcome.

\section{Adaptation outcomes}

The decision to adapt was made during the intervention phase. The adaptation process was designed during week 1 on the intervention in response to the threat of COVID-19 infection in the region; and enacted during week 4 in response to the national COVID-19 directives. Using the definition proposed by Moore et al, the change was classified as an unplanned or reactive adaptation (11). The decision to adapt was a participatory effort including the CHAs and the participants; however, the final decision was made by the study principal investigator (PI). All changes were intended to be made to the context in which the intervention was delivered, whilst preserving the content of the intervention (Table 1). 
Table 1

Adaptation outcomes using the framework for reporting adaptations and modifications to evidencebased interventions (FRAME)

\begin{tabular}{|c|c|c|c|}
\hline $\begin{array}{l}\text { Description and } \\
\text { goal of adaptation }\end{array}$ & $\begin{array}{l}\text { Who } \\
\text { participated } \\
\text { in the } \\
\text { decision to } \\
\text { modify? }\end{array}$ & $\begin{array}{l}\text { What is modified? } \\
\text { (Nature of content } \\
\text { modification) }\end{array}$ & Relationship fidelity/core elements \\
\hline $\begin{array}{l}\text { To facilitate weekly } \\
\text { monitoring of } \\
\text { clinical } \\
\text { measurements in } \\
\text { the context of } \\
\text { prohibited } \\
\text { research-related } \\
\text { face-to-face } \\
\text { interactions }\end{array}$ & $\begin{array}{l}\text { Principal } \\
\text { Investigator } \\
\text { CHA } \\
\text { Participants }\end{array}$ & $\begin{array}{l}\text { CONTENT: } \\
\text { Unchanged. } \\
\text { Clinical } \\
\text { measurements } \\
\text { continued on a } \\
\text { weekly basis. } \\
\text { CONTEXT: } \\
\text { Changed. } \\
\text { Original: Clinical } \\
\text { measurements } \\
\text { conducted by the } \\
\text { CHA at the FBO } \\
\text { Modification: } \\
\text { Clinical measures } \\
\text { performed by the } \\
\text { participants at } \\
\text { home. }\end{array}$ & $\begin{array}{l}\text { Fidelity: Consistent. During the face-to- } \\
\text { face format there was one absence out } \\
\text { of a total of } 20 \text { visits. This is } \\
\text { comparable with the previous cohort } \\
\text { where there were } 21 \text { absences out of } \\
429 \text { visits. During the online format, } \\
\text { there was one incomplete entry out of } 45 \\
\text { total entries. }\end{array}$ \\
\hline $\begin{array}{l}\text { To document } \\
\text { clinical } \\
\text { measurements to } \\
\text { allow the principal } \\
\text { investigator to } \\
\text { monitor status }\end{array}$ & $\begin{array}{l}\text { Principal } \\
\text { Investigator } \\
\text { CHA } \\
\text { Participants }\end{array}$ & $\begin{array}{l}\text { CONTENT: } \\
\text { Unchanged, } \\
\text { Clinical data was } \\
\text { reviewed on a } \\
\text { weekly basis } \\
\text { CONTEXT: } \\
\text { Changed. } \\
\text { Original: Data was } \\
\text { entered by CHAs } \\
\text { into the online } \\
\text { RedCap database } \\
\text { Modification: Data } \\
\text { was posted by } \\
\text { participants in the } \\
\text { WhatsApp mobile } \\
\text { application and } \\
\text { then uploaded by } \\
\text { the CHA to the } \\
\text { RedCap database. }\end{array}$ & $\begin{array}{l}\text { Fidelity: Consistent. The ability of the PI } \\
\text { to monitor hinged on the data entered } \\
\text { (see row above) }\end{array}$ \\
\hline
\end{tabular}




\begin{tabular}{|llll|}
\hline $\begin{array}{l}\text { Description and } \\
\text { goal of adaptation }\end{array}$ & $\begin{array}{l}\text { Who } \\
\text { participated } \\
\text { in the } \\
\text { decision to } \\
\text { modify? }\end{array}$ & $\begin{array}{l}\text { What is modified? } \\
\text { (Nature of content } \\
\text { modification) }\end{array}$ & Relationship fidelity/core elements \\
\hline $\begin{array}{l}\text { To provide } \\
\text { participants with } \\
\text { an alternative to } \\
\text { the liquid LCD } \\
\text { formulation }\end{array}$ & $\begin{array}{l}\text { Principal } \\
\text { Investigator }\end{array}$ & $\begin{array}{l}\text { CONTENT: } \\
\text { Unchanged. The } \\
\text { daily calorie }\end{array}$ & $\begin{array}{l}\text { Fidelity: Partially consistent. One } \\
\text { participant experienced some difficulty } \\
\text { both sourcing and preparing the solid } \\
\text { LCD. }\end{array}$ \\
& Participants & $\begin{array}{l}\text { remained at } \\
\text { 840kcal / day. }\end{array}$ & \\
& Dietician & $\begin{array}{l}\text { CONTEXT: } \\
\text { Changed }\end{array}$ & \\
& $\begin{array}{l}\text { Original: Diet } \\
\text { comprised mainly } \\
\text { of a liquid } \\
\text { formulation. }\end{array}$ \\
& $\begin{array}{l}\text { Modification: Diet } \\
\text { comprised of a } \\
\text { mixture of solid } \\
\text { and liquid } \\
\text { formulation }\end{array}$ \\
\hline
\end{tabular}

The first adaptation was made to the context in which the clinical measurements were taken. In the original protocol, participants were measured on a weekly basis by trained $\mathrm{CHA}$ at the FBO community site. However, in the modified version, participants were taught how to self-monitor and issued with the glucometers, scales and BP machines as necessary; during week 4 of the intervention, participants started to self-monitoring at home in accordance with the weekly protocol.

The second adaptation was made to the way the data was entered. Originally, clinical measurements were entered by CHAs into the online RedCap database on the day that participants came to be measured; the data were immediately accessible by the study PI. In the adapted protocol, participants self-monitoring at home posted their readings in the WhatsApp mobile application as soon as the measurements were done. As the PI was a member of the online group, the data were still immediately accessible. The designated $\mathrm{CHA}$ in the chat then entered the data to RedCap.

The third adaptation was to the LCD formulation. During week 8 of the intervention, the supply chain for the Glucerna ${ }^{\circledR}$ was interrupted. Online Zoom meetings with the study dietician were arranged within the week, and under her guidance, participants learned how to create nutritionally balanced solid meals of the same caloric content ( $840 \mathrm{kcal} / \mathrm{day})$, using ingredients that were either locally produced or readily available.

\section{Implementation outcomes}

Fidelity to the 12-week duration 
Review of the attendance register showed that all five participants remained in the study for the 12-week duration.

\section{Fidelity to the weekly monitoring}

During the 12-week intervention period, there were approximately 3000 total WhatsApp entries for these five participants, some 800 more than the previous group of seven participants at the same FBO site who were governed by the original protocol. Posts were made almost daily with conversations initiated by both CHAs and participants. Most participants submitted their readings within the $24 \mathrm{hr}$ period; participants who could not submit on the scheduled day e.g., because of work, took the initiative to reschedule to another day within the same week. During the modified online format, there was one incomplete entry out of 45 total entries. This was an increased fidelity over the face-to-face format for this same cohort where there was one absence out of a total of 20 visits - this was comparable with the data from the previous cohort who followed the original protocol where there were 21 absences out of 429 visits.

\section{Fidelity to the daily caloric allowance}

WhatsApp conversations were interspersed with original recipes and pictures of these meals that participants had created based on the solid meal plan (adaptation \#3). This supportive environment allowed for opening up about any perceived 'slip-ups' in dietary allowance. One participant reported some financial difficulty in sourcing the meals, as the Glucerna had been provided free of charge by the study and the responsibility to purchase meals, whether solid or liquid, was an unexpected burden. The same participant also had some difficulty determining non-exact portion sizes e.g., medium orange.

\section{Intervention outcomes}

Over the 12-week intervention period, one participant gained $0.4 \mathrm{~kg}$ whilst the remaining four participants lost $11.3-14.3 \mathrm{~kg}$. Change in systolic BP ranged from $-21 \mathrm{mmHg}$ to $+8 \mathrm{mmHg}$ and diastolic BP from $20 \mathrm{mmHg}$ to $+7 \mathrm{mmHg}$. By the end of the intervention, all three participants who were hypertensive either reduced or discontinued their anti-hypertensive medications; and all five participants achieved induction of diabetes remission based on both a FBG of $<7 \mathrm{mmol} / \mathrm{I}$ and an $\mathrm{A} 1 \mathrm{C}$ of $<6.5 \%$. This compares to the previous face-to-face cohort where the average weight loss $6.8 \mathrm{kgs}$ and systolic BP and diastolic BP decreased by $10 \mathrm{mmHg}$ and $8 \mathrm{mmHg}$ respectively. $60 \%$ achieved induction of T2DM by HbA1C threshold and $90 \%$ by FBG threshold.

\section{Discussion}

In an era of restricted movement, where systemic adaptions including telemedicine and extended drug refills have been used to buffer the gap, the success of this shift in patient monitoring for the BDRS2 offers an additional option of patient contact and support for the larger healthcare system and is in keeping with the call from WHO for countries to "find innovative ways to ensure that essential services for NCDs continue, even as they fight COVID-19" (3). 
The modifications presented here, even though unplanned, maintained fidelity for the most part, to the key components of the original BDRS2 protocol whilst improving logistical fit to the current pandemic climate.

There was improved fidelity to the attendance schedule which was probably due to the simplicity and flexibility of home-monitoring and data submission as compared to travelling to a community location for a specified time. On the other hand, we realise that the fidelity to the meal plan was stymied by the unexpected financial responsibility that was transferred to the participant, and the relatively truncated time that was allotted to instructing them on solid meal preparations. Future studies, including those undergoing unplanned adaptations, should be mindful of these pitfalls and wherever possible, dedicate additional time and resources to these areas.

The modified protocol also potentially provides a solution to other limitations of the face-to-face meetings. Firstly, the number of participants accommodated on a weekly basis was limited by the space available. A fully online protocol or a hybrid system of face-to-face interspersed with mobile selfassessments would allow for enrolment of larger numbers. This system also transfers a greater responsibility to participants during the intensive phase, which could potentially promote independence in the post-intervention era.

Although qualitative data from previous studies suggest that participants are amenable to the rigidity of the low-calorie liquid meal plan, the switch to comparably low-cost, locally sourced, solid recipes offer a solution to two limitations of the liquid formulation. Firstly, the commercially available liquid formulation is relatively costly, which could negatively impact expansion and sustainability outside of a research setting where the drinks are not provided to clients; and secondly, switching to solid meals offers greater variety which could positively impact acceptability.

The fact that participants were still able to lose weight during the adapted period speaks to the importance of building social support and self-efficacy threads into the design of an intervention. The importance of the group dynamic in the success of self-monitoring must be considered as individualised attention may require input from an alternative support system, namely the primary care physician, which may result in an increased burden on the healthcare system.

\section{Conclusion}

These results suggest that the BDRS2 is adaptable from a fully face-to-face protocol to a fully online format whilst maintaining fidelity to the key intervention elements and producing similar clinical outcomes; thereby impacting health not just within the community but within the home.

Given that this was a small study, there is scope for comparative studies examining fully face-to- face vs fully virtual implementation strategies, and feasibility studies exploring the practicality of a hybrid implementation strategy. Additional, proactive contextual modifications can be made to the existing protocol to increase the fit of the intervention to other community sites e.g., service clubs. 


\section{Declarations}

\section{Ethics approval:}

This study was approved by the joint The University of the West Indies / Ministry of Health Institutional Review Board. 180301A.

\section{Consent to participate:}

$\mathrm{n} / \mathrm{a}$

\section{Consent for publication:}

$\mathrm{n} / \mathrm{a}$

\section{Availability of data and materials:}

The datasets used and/or analysed during the current study are available from the corresponding author on reasonable request.

\section{Competing interests:}

The authors declare that they have no competing interests.

\section{Funding:}

Funding was provided by The University of the West Indies Campus Research Awards. The funders did not have a role in the design of the study or the collection, analysis, and interpretation of data or in writing the manuscript.

\section{Authors' contribution:}

KQ contributed to the design of the work, the acquisition, analysis, and interpretation of data and writing the draft and final manuscript.

MM contributed to the analysis, and interpretation of data and writing the draft and final manuscript.

$\mathrm{CH}$ contributed to the analysis, and interpretation of data and writing the final manuscript. 
$\mathrm{HH}$ contributed to the interpretation of data and writing the draft and final manuscript.

$\mathrm{IH}$ contributed to the interpretation of data and writing the final manuscript.

SJ contributed to the interpretation of data and writing the final manuscript.

NG contributed to the design of the work, interpretation of data and the writing the draft and final manuscript.

NSG contributed to the acquisition and analysis of data and writing the draft and final manuscript.

All authors read and approved the final manuscript.

\section{Acknowledgements:}

$\mathrm{n} / \mathrm{a}$

\section{References}

1. Hill CJ, Joonas K. The impact of unacceptable wait time on health care patients' attitudes and actions. Health Mark Q. 2005;23(2):69-87.

2. Checkley W, Ghannem H, Irazola V, Kimaiyo S, Levitt NS, Miranda JJ, et al. Management of NCD in Low- and Middle-Income Countries. Glob Heart. 2014 Dec 1;9(4):431-43.

3. COVID-19 significantly impacts health services for noncommunicable diseases [Internet]. [cited 2021 Apr 29]. Available from: https://www.who.int/news/item/01-06-2020-covid-19-significantly-impactshealth-services-for-noncommunicable-diseases

4. International Diabetes Federation. COVID-19 and diabetes - Q\&A with IDF President [Internet]. 2020 [cited 2021 Apr 29]. Available from: https://www.youtube.com/watch?v=4OLOcmFc1yA

5. Information note on COVID-19 and NCDs [Internet]. [cited 2021 Apr 29]. Available from: https://www.who.int/publications/m/item/covid-19-and-ncds

6. Barone MTU, Harnik SB, de Luca PV, Lima BL de S, Wieselberg RJP, Ngongo B, et al. The impact of COVID-19 on people with diabetes in Brazil. Diabetes Res Clin Pract. 2020 Aug 1;166:108304.

7. Harjumaa M, Absetz P, Ermes M, Mattila E, Männikkö R, Tilles-Tirkkonen T, et al. Internet-Based Lifestyle Intervention to Prevent Type 2 Diabetes Through Healthy Habits: Design and 6-Month Usage Results of Randomized Controlled Trial. JMIR Diabetes [Internet]. 2020 Aug 11 [cited 2021 Apr 29];5(3). Available from: https://www.ncbi.nlm.nih.gov/pmc/articles/PMC7448183/

8. Quimby KR, Sobers N, George C, Greaves N, Browman-Jones F, Samuels TA. Implementation of a Community-Based Low-Calorie Dietary Intervention for the Induction of Type-2 Diabetes and PreDiabetes Remission: A Feasibility Study Utilising a Type-2 Hybrid Design I Preprint available at 
Research Square [Internet]. 2021 [cited 2021 Apr 29]. Available from:

https://www.researchsquare.com/article/rs-447846/v1

9. Miller CJ, Wiltsey-Stirman S, Baumann AA. Iterative Decision-making for Evaluation of Adaptations (IDEA): A decision tree for balancing adaptation, fidelity, and intervention impact. J Community Psychol. 2020 May;48(4):1163-77.

10. Wiltsey Stirman S, Baumann AA, Miller CJ. The FRAME: an expanded framework for reporting adaptations and modifications to evidence-based interventions. Implement Sci IS [Internet]. 2019 Jun 6 [cited 2021 Apr 29];14. Available from: https://www.ncbi.nlm.nih.gov/pmc/articles/PMC6554895/

11. Moore JE, Bumbarger BK, Cooper BR. Examining Adaptations of Evidence-Based Programs in Natural Contexts. J Prim Prev. 2013 Jun 1;34(3):147-61.

\section{Supplementary Files}

This is a list of supplementary files associated with this preprint. Click to download.

- StaRIchecklistadaptBDRS2.docx 